\title{
GASEOUS EMISSION AND THERMAL ANALYSIS DURING CO-COMBUSTION OF OIL SHALE SEMI- COKE AND SAWDUST USING TG-FTIR
}

\author{
WANG QING ${ }^{(\mathrm{a})^{*}}$, XUAN YANG ${ }^{(\mathrm{a}, \mathrm{b})}$, LIU HONGPENG $^{(\mathrm{a})}$, \\ LI XIYAN $^{(a)}$, CHI MINGSHU ${ }^{(a)}$
}

(a) Engineering Research Centre of Oil Shale Comprehensive Utilization, Ministry of Education, Northeast Dianli University, Jilin 132012, Jilin Province, China

(b) State Nuclear Electric Power Planning Design \&Research Institute, 100095, Beijing City, China

\begin{abstract}
The kinetics and thermal characteristics of oil shale semi-coke and sawdust, including their blends, during co-combustion were investigated using a non-isothermal thermogravimetric analyzer (TGA). The ratio of semicoke to sawdust in the blends by mass was set as 10:0, 9:1, 8:2, 7:3, 6:4, 5:5 and 0:10. The combustion performance of samples improved significantly with increasing sawdust proportion in the mixture and rising heating rate. The kinetic analysis demonstrated that the distributed activation energy model (DAEM) could well describe the value of apparent activation energy at different fixed conversion values. Gaseous emission analysis by using the coupled Fourier transform infrared spectroscopy (FTIR) demonstrated that organic compounds were produced by the pyrolysis of sawdust, while inorganic compounds were generated during the whole combustion process. Most of the inorganic compounds were $\mathrm{CO}_{2}$ and $\mathrm{CO}$. Seldom $\mathrm{SO}_{2}$ and $\mathrm{NO}_{x}$ were released at the initial stage. The results obtained indicated that the blends may improve the combustion performance of oil shale semi-coke and sawdust.
\end{abstract}

Keywords: oil shale semi-coke, saw dust, TG-FTIR, gaseous product emissions, reaction kinetics.

\section{Introduction}

Oil shale, widely distributed around the world, is defined as a kind of energy, being an important supplement to oil and gas resources. In 2014, the shale oil production in the world was $14 \times 10^{5} \mathrm{t}$, including $7.8 \times 10^{5} \mathrm{t}$ in China [1]. However, semi-coke, obtained from oil shale retorting, is a lowgrade fuel with low volatility and contains a lot of phenols - polycyclic

\footnotetext{
* Corresponding author: e-mail rlx888@126.com
} 
aromatic hydrocarbons (PAHs) [2]. Usually, oil yield after pyrolysis in retorts is about $6.0-17.0 \%$. Therefore, around $10-30$ tons of retorting residue per ton of oil is left after production [3]. In China, all the oil shale semi-coke generated is deposited in open dumps, which poses a great threat to the environment and will gradually become a bottleneck in the development and utilization of oil shale [4].

Therefore, a significant issue for researchers is how to treat semi-coke effectively. A viable solution is to burn it as fuel, which way has been proposed to reduce environmental pollution and recycle the energy embedded in semi-coke. Kuusik et al. [5] proposed a method of burning semi-coke in fluidized-bed boilers for power generation. Kaljuvee et al. [6] investigated the combustion behavior of oil shale semi-coke in a circulating fluidized bed (CFB) boiler and found that $\mathrm{SO}_{2}$ could be sufficiently fixed.

Recently, the co-combustion of semi-coke and other good quality solid fuels has attracted interest of many researchers. Wang et al. [7, 8] have researched the co-combustion of oil shale semi-coke and biomass by establishing a reaction kinetics model. Sun et al. [9] investigated the cocombustion kinetic mechanisms of oil shale semi-coke and bituminous coals. The results showed that the process performance could be significantly improved by mixing semi-coke with high-calorific fuels.

At present, the wood-processing industry, one of the major domestic manufacturings in China, has excellent prospects for the future [10]. However, sawdust generated by wood processing is not fully utilized and is burned or discarded directly, except for some recycling by the agricultural and food industries.

Sawdust mainly comprises cellulose; the second most predominant component is lignin, which consists of guaiacyl, syringyl, and p-hydroxy phenyl groups. Sawdust may also contain a few hemicelluloses [11]. Owing to the advantages, such as remarkable igniting and burnout characteristics as well as low pollution, sawdust can be considered an ideal source of green energy.

Therefore, the co-combustion of semi-coke and sawdust is promising with regard to overcoming the problems touched upon above. This method will enable the full utilization of the high calorific value of sawdust to promote the combustion of the blends. In addition, the adsorption properties of semi-coke can be used to reduce the amount of poisonous gas and dust particles produced during combustion.

\section{Experimental}

\subsection{Materials}

The oil shale semi-coke (SC) sample used in this work was obtained from Fushun Oil Shale Retorting Factory. Oil shale was retorted using heat gas transfer fluids. Sawdust (SD) was provided by the Forestry Bureau of Jilin City. Samples with different blending ratios were labeled as S1, S2, S3, S4, 
S5, S6 and S7. According to the ASTM standards, the blend particle size was less than $0.076 \mathrm{~mm}$. The blending ratios (SC/SD) are given in Table 1. The data on proximate and ultimate analyses of SC and SD blends are presented in Table 2.

Table 1. Sample labels and blending ratios

\begin{tabular}{|c|c|c|c|c|c|c|c|}
\hline Sample label & S1 & S2 & S3 & S4 & S5 & S6 & S7 \\
\hline Blending ratio, SC/SD & $10: 0$ & $9: 1$ & $8: 2$ & $7: 3$ & $6: 4$ & $5: 5$ & $0: 10$ \\
\hline
\end{tabular}

Table 2. Proximate and ultimate analyses of oil shale semi-coke and sawdust samples

\begin{tabular}{|c|c|c|c|c|c|c|c|c|c|c|}
\hline Sample & \multicolumn{4}{|c|}{$\begin{array}{c}\text { Proximate, } \\
\%\end{array}$} & $\begin{array}{c}\text { Net heating } \\
\text { value }\end{array}$ & \multicolumn{5}{c|}{$\begin{array}{c}\text { Ultimate, } \\
\%\end{array}$} \\
\cline { 2 - 12 } & $\mathrm{C}_{\mathrm{ad}}$ & $\mathrm{H}_{\mathrm{ad}}$ & $\mathrm{O}_{\mathrm{ad}}$ & $\mathrm{N}_{\mathrm{ad}}$ & $\mathrm{S}_{\mathrm{ad}}$ & $\mathrm{Q}_{\text {net,ar }}, \mathrm{kJ} \cdot \mathrm{kg}^{-1}$ & $\mathrm{M}_{\mathrm{ad}}$ & $\mathrm{V}_{\mathrm{ad}}$ & $\mathrm{A}_{\mathrm{ad}}$ & $\mathrm{FC}_{\mathrm{ad}}$ \\
\hline $\mathrm{SC}$ & 5.73 & 0.37 & 4.35 & 0.74 & 0.15 & 1912.55 & 1.10 & 7.68 & 87.44 & 3.78 \\
$\mathrm{SD}$ & 45.55 & 5.42 & 33.31 & 0.60 & 0.17 & 13617.06 & 6.71 & 74.90 & 8.24 & 10.15 \\
\hline
\end{tabular}

Note: ${ }_{\text {ad }}$ - on air-dry basis.

\subsection{Experimental setup}

TGA was performed using a Mettler-Toledo TGA/DSC analyzer under atmospheric pressure. The sample $(8 \mathrm{mg})$ was placed in the instrument under air $(50 \mathrm{ml} / \mathrm{min})$ and the experiments were performed at different heating rates $\left(10,20,40\right.$ and $\left.80{ }^{\circ} \mathrm{C} / \mathrm{min}\right)$ within the temperature range of $50-950{ }^{\circ} \mathrm{C}$. Weight loss during combustion was determined after the sample was burned out. The FTIR spectrum was detected by an IS10 Spectrometer (Nicolet Company, US). The sampling parameters were as follows: resolution $4 \mathrm{~cm}^{-1}$, number of scans 4 , and wave number range $4000-600 \mathrm{~cm}^{-1}$.

\section{Results and discussion}

\subsection{Thermogravimetric experiment analysis}

The combustion parameters were determined through thermogravimetric (TG) and derivative thermogravimetric (DTG) curves. Figure 1 shows the TG-DTG curves obtained at a heating rate of $20^{\circ} \mathrm{C} / \mathrm{min}$ for samples S1-S7. There are three stages of weight loss for oil shale semi-coke and sawdust, and four stages for their blends. For the blends, the first stage corresponds to moisture evaporation at temperatures ranging from 50 to $120^{\circ} \mathrm{C}$, which is called moisture evaporation stage. The second stage consists of the release and burning of volatiles in sawdust at temperatures ranging from 200 to $360{ }^{\circ} \mathrm{C}$ and is named low-temperature stage. The third stage, called mediumtemperature stage, is mostly the combustion of char in the biomass and of the fixed carbon in semi-coke in the temperature range of 360 to $600{ }^{\circ} \mathrm{C}$. The fourth stage ranging from 600 to $950{ }^{\circ} \mathrm{C}$ involves the minerals decomposi- 
tion in the semi-coke, and represents high-temperature stage. Specially for semi-coke, the second and third stages can be regarded as one stage because of its low content of volatiles. Similarly, there is no stage four in the combustion of sawdust because the material contains no minerals.

(a)

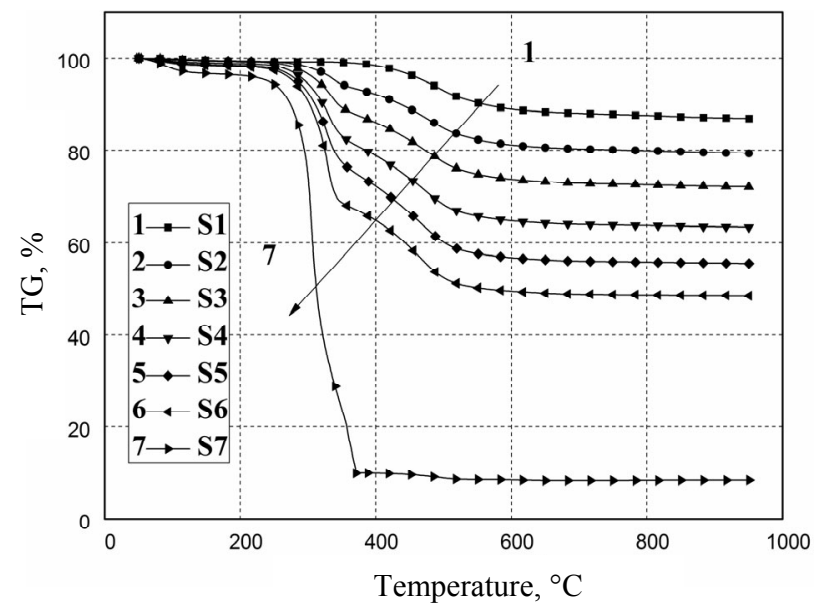

(b)

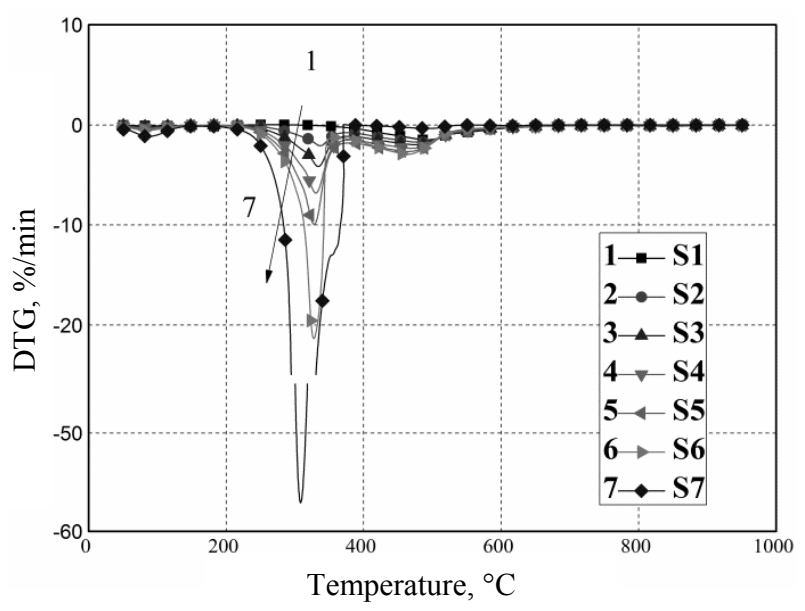

Fig. 1. (a) Thermogravimetric (TG) and (b) derivative thermogravimetric (DTG) combustion curves for samples $\mathrm{S} 1$ to $\mathrm{S} 7$ at a heating rate of $20^{\circ} \mathrm{C} / \mathrm{min}$.

It may be observed that the ash content of sawdust is obviously lower than that of oil shale semi-coke, which is consistent with the data of proximate analysis. With increasing proportion of sawdust in the blend, the mass loss degree on TG curves increases. Besides, the width and temperature 
of the peaks on the DTG curves of sample increase. This may be attributed to the improvement of combustion performance when sawdust is mixed with semi-coke.

Figure 2 shows the TG-DTG curves of S3 at different heating rates $\left(10,20,40\right.$, and $\left.80{ }^{\circ} \mathrm{C} / \mathrm{min}\right)$, revealing that higher heating rates are accompanied by higher reaction temperatures and higher reaction rates. Moreover, a typical phenomenon is that the peak temperature moves to the higher temperature region with increasing heating rate, meaning that the higher the heating rate is, the higher the temperature of ignition and burnout is. This is due to the exposure time being shortened at a particular temperature with the increase in the heating rate, which is demonstrated by the fact that as the gradient of particles increases, the mass and heat transfer are

(a)

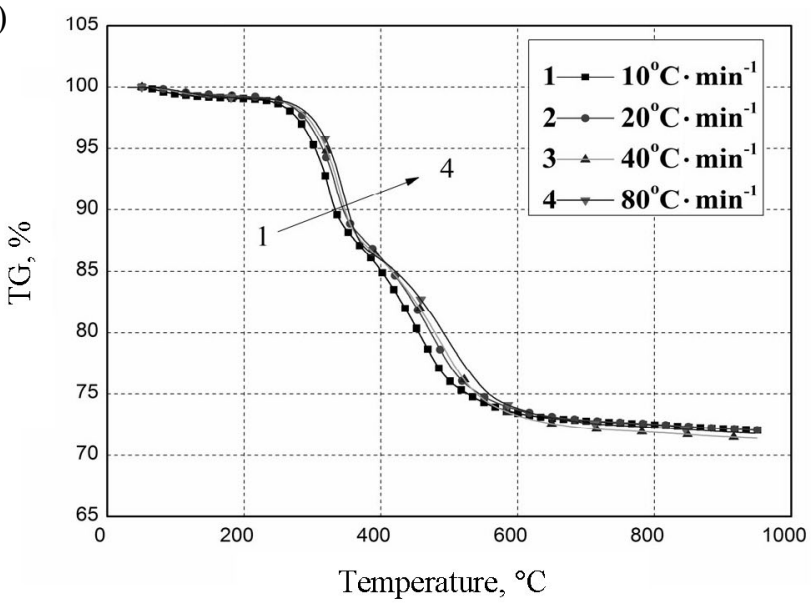

(b)

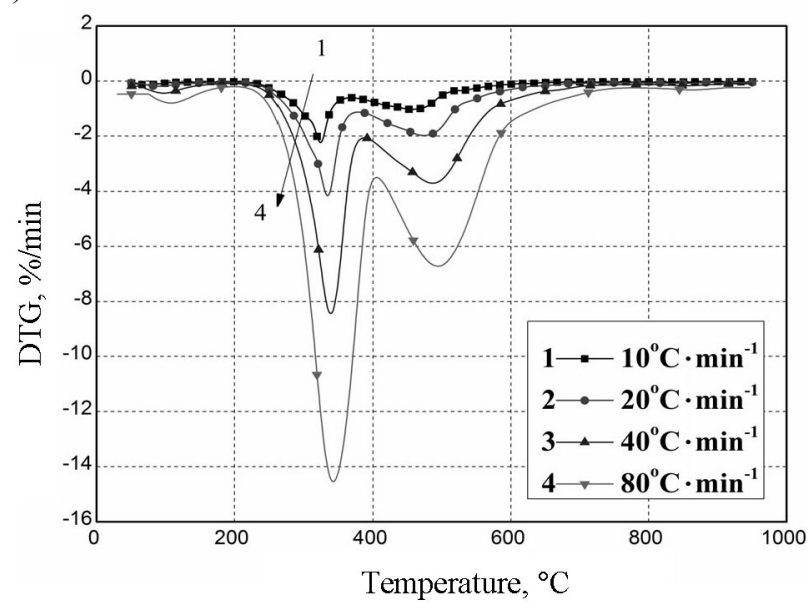

Fig. 2. (a) Thermogravimetric (TG) and (b) derivative thermogravimetric (DTG) combustion curves for sample S3 at different heating rates. 
hindered, causing local thermal lag. In addition, the short residence time led to a lack of oxygen, which not only hindered the precipitation of volatiles but also reduced the oxygen concentration on the surface of the internal fixed carbon particles, affecting the overall sample activation.

Combustion parameters can be used to describe the combustion behavior in detail. The ignition temperature $T_{i}$ is obtained by the TG-DTG extrapolation method [12]. The maximum and average burning rates are expressed as $(d w / d t)_{\max }$ and $(d w / d t)_{\text {mean }}$, respectively. The burnout temperature $T_{h}$ is defined as the value on the unchanged DTG curves, which means that the reaction is accomplished $[13,14]$. To further investigate the combustion reaction of samples, a parameter called the combustion performance index, $S$, was introduced [15]. $S$ is computed as follows:

$$
S=\frac{(d w / d t)_{\max } \cdot(d w / d t)_{\text {mean }}}{T_{i}^{2} \cdot T_{b}},
$$

where $(d w / d t)_{\max }$ is the maximum burning rate, $(d w / d t)_{\text {mean }}$ is the average burning rate, $T_{i}$ is the ignition temperature, and $T_{b}$ is the burnout temperature. In unit time, the higher the value of $S$ is, the better the general combustion performance is.

Table 3 shows the combustion parameters of samples.

It is found that the lower the heating rate is, the easier the ignition and burning out of the fuel are. Besides, it is obvious that with increasing sawdust proportion in the blend, the initial ignition and burnout temperatures of samples decreased gradually while the reaction rate rose sharply, which indicated that the combustion performance of samples could be improved. From the change in $S$ it can be observed that increasing the heating rate and sawdust proportion enhances the reaction ability of samples per unit time. The variation in $S$ does not keep pace with the change in sawdust proportion, especially for samples S4 and S5, which is mainly related to the dramatically shortened burnout time.

\subsection{Kinetics analysis}

The distributed activation energy model (DAEM) has been extensively used to analyze complex reactions, such as the combustion of fossil fuels and the pyrolysis of biomass $[16,17]$. In this paper, the calculation is based on the integral method proposed by Miura [18]. It is assumed that the whole thermal conversion process of oil shale semi-coke, sawdust and their blends under air atmosphere is composed of a set of first-order reactions occurring successively. According to the Miura method, the apparent activation energy $E$ is estimated from a set of four TG experiments at different heating rates. The model is expressed as:

$$
\frac{d V}{d t}=\frac{A}{\beta}\left(V-V^{*}\right) \exp (-E / R T)
$$


Table 3. The combustion parameters of samples at different ratios and heating rates

\begin{tabular}{|c|c|c|c|c|c|c|}
\hline Sample & $\begin{array}{l}\text { Heating rate, } \\
{ }^{\circ} \mathrm{C} / \mathrm{min}\end{array}$ & $\mathrm{T}_{\mathrm{i}},{ }^{\circ} \mathrm{C}$ & $\mathrm{T}_{\mathrm{b}},{ }^{\circ} \mathrm{C}$ & $\begin{array}{c}(d w / d t)_{\text {mean }} \\
\% / \mathrm{s}\end{array}$ & $\begin{array}{c}(d w / d t)_{\max }, \\
\% / \mathrm{s}\end{array}$ & $\mathrm{S} \times 10^{-8}$ \\
\hline \multirow{4}{*}{ S1 } & 10 & 404.0 & 916.9 & 0.140 & 0.738 & 0.073 \\
\hline & 20 & 420.3 & 912.9 & 0.290 & 1.490 & 0.251 \\
\hline & 40 & 428.1 & 911.8 & 0.568 & 2.907 & 1.132 \\
\hline & 80 & 437.2 & 892.2 & 1.793 & 6.041 & 6.208 \\
\hline \multirow{4}{*}{ S2 } & 10 & 292.7 & 883.3 & 0.225 & 1.086 & 0.256 \\
\hline & 20 & 296.8 & 883.6 & 0.460 & 2.079 & 0.786 \\
\hline & 40 & 303.5 & 886.7 & 0.908 & 3.606 & 3.161 \\
\hline & 80 & 306.4 & 886.4 & 1.820 & 6.900 & 12.84 \\
\hline \multirow{4}{*}{ S3 } & 10 & 286.4 & 847.4 & 0.311 & 2.228 & 0.671 \\
\hline & 20 & 293.7 & 852.0 & 0.621 & 4.152 & 2.682 \\
\hline & 40 & 297.1 & 855.1 & 1.273 & 8.413 & 10.29 \\
\hline & 80 & 301.7 & 858.1 & 2.515 & 14.54 & 30.46 \\
\hline \multirow{4}{*}{ S4 } & 10 & 277.6 & 798.7 & 0.394 & 3.336 & 1.188 \\
\hline & 20 & 292.1 & 804.0 & 0.814 & 6.795 & 5.595 \\
\hline & 40 & 296.2 & 807.5 & 1.619 & 17.17 & 25.96 \\
\hline & 80 & 298.6 & 803.3 & 3.223 & 24.09 & 68.62 \\
\hline \multirow{4}{*}{ S5 } & 10 & 270.6 & 705.5 & 0.494 & 4.999 & 3.114 \\
\hline & 20 & 290.6 & 711.2 & 0.987 & 9.932 & 11.82 \\
\hline & 40 & 295.8 & 714.6 & 1.949 & 25.19 & 48.16 \\
\hline & 80 & 296.4 & 726.8 & 3.931 & 32.14 & 147.1 \\
\hline \multirow{4}{*}{ S6 } & 10 & 267.7 & 636.3 & 0.589 & 6.442 & 4.202 \\
\hline & 20 & 288.4 & 657.7 & 1.146 & 21.34 & 26.12 \\
\hline & 40 & 295.4 & 675.8 & 2.299 & 28.95 & 79.16 \\
\hline & 80 & 295.5 & 687.0 & 4.627 & 38.12 & 168.3 \\
\hline \multirow{4}{*}{ S7 } & 10 & 291.1 & 514.5 & 1.051 & 51.18 & 76.57 \\
\hline & 20 & 287.2 & 540.8 & 2.035 & 57.08 & 164.6 \\
\hline & 40 & 293.9 & 560.6 & 4.058 & 67.59 & 429.7 \\
\hline & 80 & 289.5 & 594.8 & 8.147 & 80.28 & 845.1 \\
\hline
\end{tabular}

where $V$ and $V^{*}$ represent respectively the amount of volatiles evolved and the effective amount of volatile for the reaction at the temperature $T, A$ is the pre-exponential factor, $\beta$ is the heating rate and $E$ is the distribution of the activation energy, meaning the variation of activation energies of the above independent first-order reactions. The integrated form of Equation (2) is:

$$
V=V^{*}\left[1-\exp \left(\frac{A}{\beta} \int_{o}^{t} e^{-E / R T} d t\right)\right] .
$$

According to the Miura integral method, Equation (3) can be integrated for a constant heating rate as follows:

$$
1-\frac{V}{V^{*}} \cong \exp \left[\frac{A R T}{\beta E} \exp (-E / R T)\right] \text {. }
$$


Equation (4) can be expressed as:

$$
\ln \left(\frac{\beta}{T^{2}}\right)=\ln \left(\frac{A R}{E}\right)-\ln \left[-\ln \left(1-\frac{V}{V^{*}}\right)\right]-\frac{E}{R} \frac{1}{T} .
$$

By using an approximate treatment, $1-V / V^{*}=0.58$, Equation (5) is further simplified as follows:

$$
\ln \left(\frac{\beta}{T^{2}}\right)=\ln \left(\frac{A R}{E}\right)+0.6075-\frac{E}{R} \frac{1}{T} .
$$

The whole system of reactions, which occur at different temperatures corresponding to the successive mass losses at a fixed heating rate, may be approximated. Equation (6) makes it easier to use the DAEM method to obtain kinetic parameters. For the same $V / V^{*}$ at different heating rates, Equation (6) provides a linear relationship between $\beta / T^{2}$ and $1 / T$ with the slope of $E / R$. Finally, the activation energy $E$ can be estimated by the slope of the linear-fitting curve from the correlated experimental data. In this work, 48 conversion points were selected by:

$$
V / V^{*}=0.02 n(1 \leq n \leq 48, n \in Z) .
$$

The activation energy curves at different conversion rates are illustrated in Figure 3. The $E$ value of S1 increased slowly until a conversion rate of 0.7 , and then increased significantly to the end of the reaction, which means that semi-coke is easy to react during the low- and medium-temperature stages but difficult to burn out at the high-temperature stage. The $E$ value of $\mathrm{S} 7$ increased sharply in the initial stage and peaked at a conversion rate of 0.3 , indicating that considerable energy was consumed during the pyrolysis

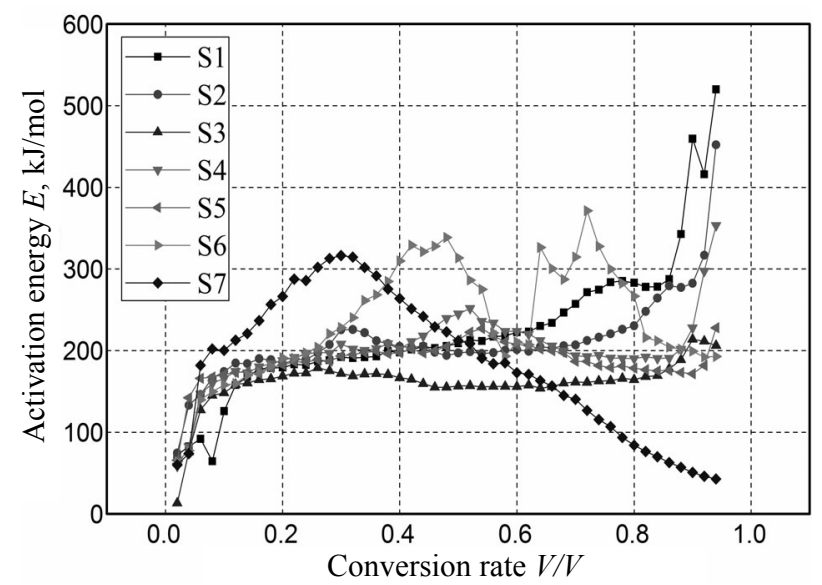

Fig. 3. Activation energies for samples $\mathrm{S} 1$ to $\mathrm{S} 7$ as a function of conversion rate. 
process of sawdust. Then, a great amount of volatiles burned rapidly in sawdust, reducing the threshold energy at which the reactant turns into a product. Hence, the apparent activation energy decreased gradually until the end of the reaction.

Upon addition of sawdust, the activation energy curves tend to be smooth, which can be interpreted by the improved combustion performance of samples S1 and S7. The apparent peaks in the curves of S6 demonstrate that the combustion underwent several stages when the proportion of sawdust was $50 \%$.

\subsection{Infrared spectral analysis}

In order to clearly understand the phenomena of weight loss and gas release in the combustion process, Fourier transform infrared spectroscopy (FTIR) was used to study the gaseous products of samples combustion.

As shown in Figure 4, the change in absorbance in the Gram-Schmidt curves of samples S1 to S7 during combustion reflects the change in the gaseous product emissions in the process. Like the DTG curves in Figure 1, these curves contain apparent peaks in the range $200-360{ }^{\circ} \mathrm{C}$, which grow dramatically with the increasing proportion of sawdust in the mixture, demonstrating that the volatiles in sawdust dominated the combustion process. In this stage, the growth of peaks is attributed to the pyrolysis of cellulose after ignition, while the aggregate structure of the glucose residue and the absence of aromatic hydrocarbons favour its decomposition. Moreover, the decomposition and combustion of lignin containing a benzene ring further contribute to the process. In addition, small amounts of hemicelluloses, alkaloids and other substances also participate in this stage. The peaks in the range $360-600{ }^{\circ} \mathrm{C}$ represent the quantity of gas released in the

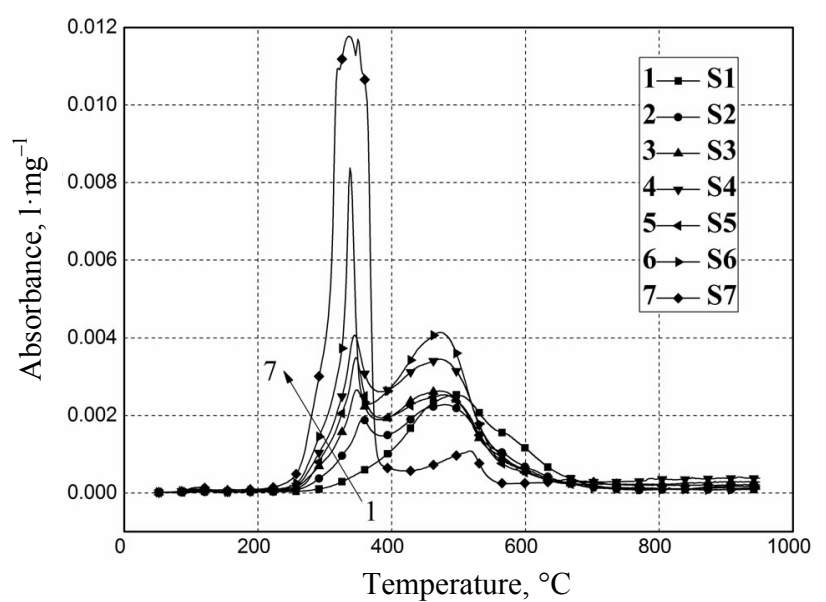

Fig. 4. Gram-Schmidt curves for the combustion of samples $\mathrm{S} 1$ to $\mathrm{S} 7$ at a heating rate of $20^{\circ} \mathrm{C} / \mathrm{min}$. 
fixed carbon combustion. In addition, owing to higher internal moisture content and the decomposition of ammonium salt, S7 has a slight peak during the initial stages.

Figure 5 shows the absorbance in the Gram-Schmidt curves of S3 at different heating rates in the combustion process that reflected the variation in gaseous product emissions in the reaction. In addition, the temperatures at which the peaks appeared corresponded to those in the DTG curve in Figure 2. The absorption rates were dependent upon the heating rate, especially when it increased from 10 to $40{ }^{\circ} \mathrm{C} / \mathrm{min}$, but when it increased from 40 to $80{ }^{\circ} \mathrm{C} / \mathrm{min}$, there was no apparent difference. The result can be explained by the retention of volatiles, leading to a more difficult conversion of cellulose and hemicelluloses to chars, resulting in a lower quantity of gas being released in the two zones, while the absorption intensity remained unchanged.

In order to investigate the gaseous emission of the blends of oil shale semi-coke and sawdust, S3 at a heating rate of $20{ }^{\circ} \mathrm{C} / \mathrm{min}$ is selected for further study. The characteristic FTIR absorption bands of some gases and functional groups in the gaseous combustion products of samples are given in Table 4.

In the FTIR experiments, two intense peaks were observed at $349.42{ }^{\circ} \mathrm{C}$ and $472.62{ }^{\circ} \mathrm{C}$, which represent the largest quantity of gas released in the low- and medium-temperature stages of combustion, respectively. Their infrared spectrum diagrams are shown in Figures 6 and 7.

In the low-temperature stage, the main gaseous product is $\mathrm{CO}_{2}$, while the minor product was $\mathrm{CO}$ produced by incomplete combustion. The stretching vibration bands detected at $1850-1600 \mathrm{~cm}^{-1}$ correspond to the $\mathrm{C}=\mathrm{O}$ group in the aldehyde or ketone compounds produced from the guaiacyl in lignin and

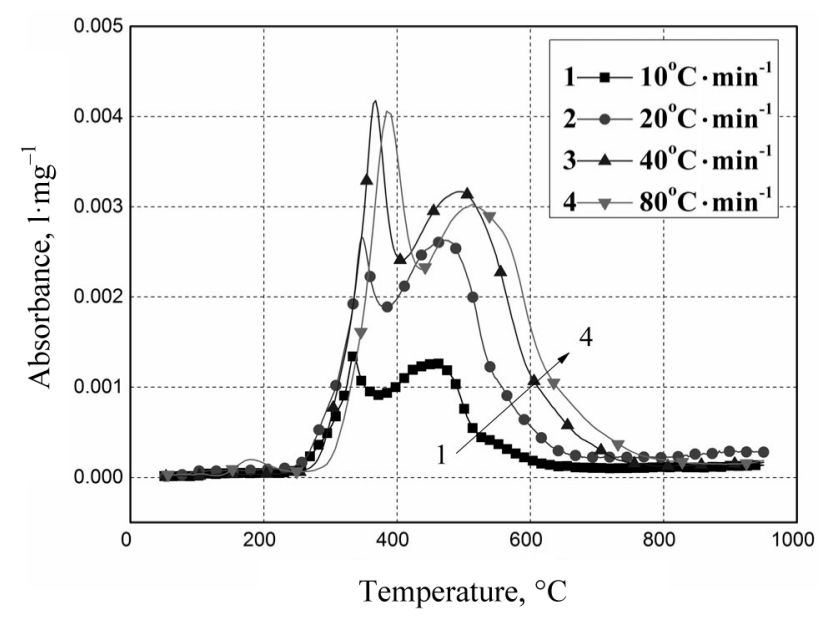

Fig. 5. Gram-Schmidt curves for the combustion of sample S3 at different heating rates. 
Table 4. Summary of the characteristic FTIR absorption bands of some gases and functional groups in the gaseous combustion products of samples

\begin{tabular}{|c|c|}
\hline Functional group & Wave number, $\mathrm{cm}^{-1}$ \\
\hline $\mathrm{CO}_{2}$ & $2400-2240$ \\
$\mathrm{CO}$ & $2240-2060$ \\
$\mathrm{H}_{2} \mathrm{O}$ & $4000-3500$ \\
$\mathrm{SO}_{2}$ & 1374 \\
$\mathrm{NO}_{2}$ & 1510 \\
$\mathrm{C}=\mathrm{O}$ & $1850-1600$ \\
$\mathrm{C}=\mathrm{C}$ & $1600-1420$ \\
$\mathrm{~S}=\mathrm{O}$ & $1420-1300$ \\
$\mathrm{C}-\mathrm{H}$ & $3000-2850,750-600$ \\
$-\mathrm{OH}$ & $4000-3500$ \\
\hline
\end{tabular}

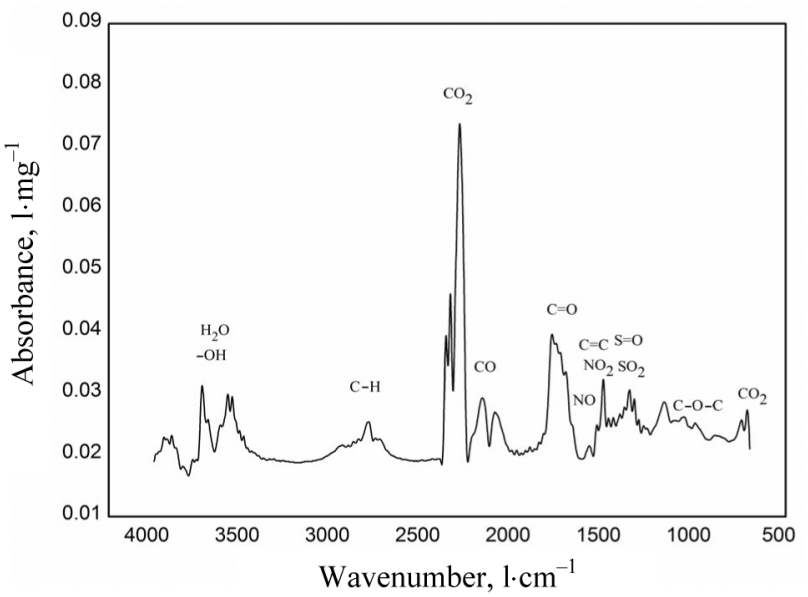

Fig. 6. FTIR spectrogram for the combustion of sample $\mathrm{S} 3$ at $349.42{ }^{\circ} \mathrm{C}$.

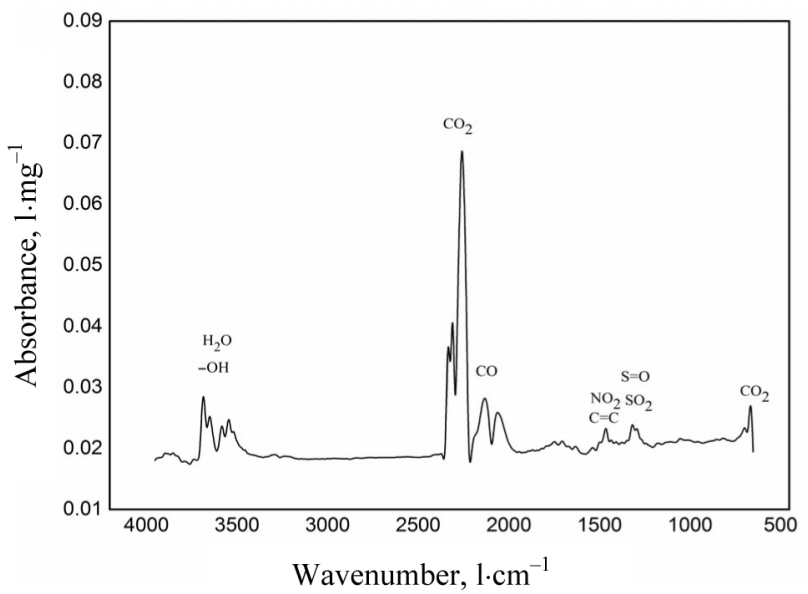

Fig. 7. FTIR spectrogram for the combustion of sample $\mathrm{S} 3$ at $472.62{ }^{\circ} \mathrm{C}$ 
the glucose residue in cellulose during pyrolysis of sawdust. The $\mathrm{C}-\mathrm{O}-\mathrm{C}$ stretching vibration bands ascribed to etheric compounds occurred in the range 1131-1077 $\mathrm{cm}^{-1}$, which may be due to the presence of some of them [19]. The $\mathrm{C}=\mathrm{C}$ stretching at $1600-1420 \mathrm{~cm}^{-1}$ is linked with an aromatic skeletal mode. There were two infrared absorption peaks for $\mathrm{C}-\mathrm{H}$ located at $3000-2850 \mathrm{~cm}^{-1}$ and $900-650 \mathrm{~cm}^{-1}$. The former was an asymmetric stretching vibration peak associated with an aldehyde compound and, less commonly, with $\mathrm{CH}_{4}$ produced by pyrolysis in the absence of oxygen. The latter was a bending vibration peak attributed to the aromatic compounds and unsaturated aliphatic hydrocarbons. In addition, the bands at 2240 $2060 \mathrm{~cm}^{-1}$ are characteristic peaks of $\mathrm{CO}$, which is mainly formed by the breaking of $\mathrm{C}-\mathrm{O}-\mathrm{C}$ and $\mathrm{C}=\mathrm{O}[20]$. All the carbon-containing compounds mentioned above can be further oxidized to $\mathrm{CO}_{2}$.

The absorbance of $-\mathrm{OH}$ stretching at $4000-3500 \mathrm{~cm}^{-1}$ is related to $\mathrm{H}_{2} \mathrm{O}$ and the phenolic hydroxyl group release. The breakdown of 1-phenylpropane, the main unit of lignin in sawdust, formed guaiacyl and 2-hydroxyphenyl functional groups. The $\mathrm{S}=\mathrm{O}$ stretching vibration peaks in the region of $1440-1300 \mathrm{~cm}^{-1}$ is attributed to some organic sulfur-oxygen compounds such as sulfones and sulfoxides [21]. In particular, the band at $1374 \mathrm{~cm}^{-1}$ is the characteristic peak of $\mathrm{SO}_{2}$. In addition, the study found that $\mathrm{NO}_{2}$ at $1510 \mathrm{~cm}^{-1}$ is released by the decomposition of nitrogen structures in the sawdust alkaloids [22].

In the low-temperature stage, the amount of $\mathrm{CO}_{2}$ decreases, while that of $\mathrm{CO}$ remains the same. The appearance of the $-\mathrm{OH}$ functional group mainly depends on the precipitation of cresol and p-cresol, or the release of $\mathrm{H}_{2} \mathrm{O}$. $\mathrm{SO}_{2}$ is released by heterocyclic chemicals containing sulfur and the decomposition of thiophene compounds from oil shale after pyrolysis. In addition, $\mathrm{NO}_{\mathrm{x}}$ was derived from the combination of $\mathrm{HCN}$ (from coke nitrogen) and oxygen [23]. During the reaction, the $\mathrm{C}-\mathrm{O}-\mathrm{C}$ is cleaved first, followed by the $\mathrm{C}=\mathrm{O}$, releasing $\mathrm{CO}_{2}$ and $\mathrm{H}_{2} \mathrm{O}$.

In the FTIR analysis section, the absorption bands of $\mathrm{CO}_{2}\left(2306 \mathrm{~cm}^{-1}\right)$, $\mathrm{CO}\left(2182 \mathrm{~cm}^{-1}\right), \mathrm{SO}_{2}\left(1374 \mathrm{~cm}^{-1}\right)$, and $\mathrm{NO}_{2}\left(1510 \mathrm{~cm}^{-1}\right)$ gases were identified. The FTIR absorbance in characteristic wave numbers versus temperature curves for these gases from the combustion of samples are illustrated in Figure 8.

From Figure 8a it can be observed that the main gaseous combustion product of all the samples is $\mathrm{CO}_{2}$. There are two peaks for samples $\mathrm{S} 2$ to $\mathrm{S} 7$ differing considerably in height, which confirms that $\mathrm{CO}_{2}$ is mainly produced in the low-temperature stage of volatiles combustion. At the end of the experiments, the curves tended to zero, revealing that the carbonate content in the samples decreased.

As shown in Figure 8b, the amount of $\mathrm{CO}$ emitted during the combustion of samples S2 and S7 are similar to that of $\mathrm{CO}_{2}$, which mainly originated from the cracking of the glycosyl group in sawdust. Considering that a huge amount of organic gaseous compounds ejects from the samples per unit of 
time during the low-temperature stage of combustion, the formation of $\mathrm{CO}$ may be mainly due to their incomplete oxidation. According to the classical shrinking-core model [24], the latter period of the test fits the internal diffusion control model for ash; the reducibility of char affects the local oxidation reaction at high temperature:

$$
\mathrm{C}+\mathrm{CO}_{2} \rightarrow 2 \mathrm{CO} .
$$

It is observed that the emissions of $\mathrm{SO}_{2}$ occurred over a narrow temperature range and remained at a low level, except for the low-temperature stage (Fig. 8c). This is due to the decomposition and oxidation of sulfurcontaining heterocyclic aromatic hydrocarbons in sawdust. Moreover, some $\mathrm{SO}_{2}$ is released by the breaking and oxidation of $\mathrm{C}-\mathrm{S}$ from thiophene material. There is hardly any variation between samples S3-S5 due to selfdesulfurization. In other words, $\mathrm{CaO}$ in semi-coke can fix $\mathrm{SO}_{2}$ in $\mathrm{CaSO}_{4}$ at an appropriate mole ratio of calcium to sulfur.

$\mathrm{NO}_{\mathrm{x}}$ is mainly existing as $\mathrm{NO}_{2}$ as demonstrated in Figure 8d. It was found that there were three absorption peaks in the curves. At the moisture evaporation stage, the peak is associated with the decomposition of nitrate. In the low-temperature zone, the combustion of pyridine, pyrrole and nitrogen-containing heterocyclic aromatic hydrocarbons results in $\mathrm{NO}_{2}$ emission [23]. In the medium-temperature zone, $\mathrm{NO}_{2}$ was generated by the decomposition of cyanide, i.e. $-\mathrm{CN}$ combined with $-\mathrm{O}$ - or oxygen to form $\mathrm{NO}$, and was then converted into $\mathrm{NO}_{2}$. The quantity of $\mathrm{NO}_{2}$ released was relatively low compared to that of $\mathrm{SO}_{2}$ according to the proximate analysis in Table 2, because a reducing atmosphere could convert $\mathrm{NO}_{2}$ to $\mathrm{N}_{2}$.

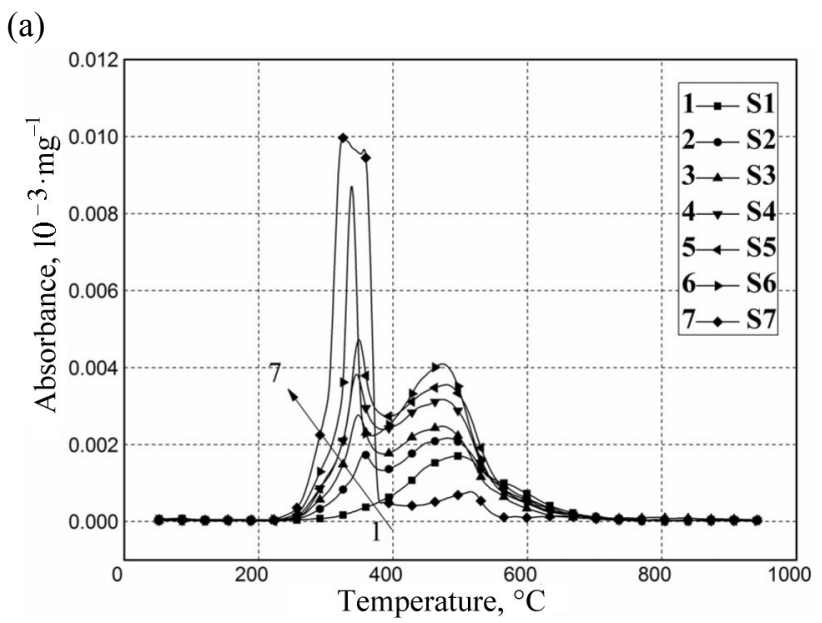


(b)

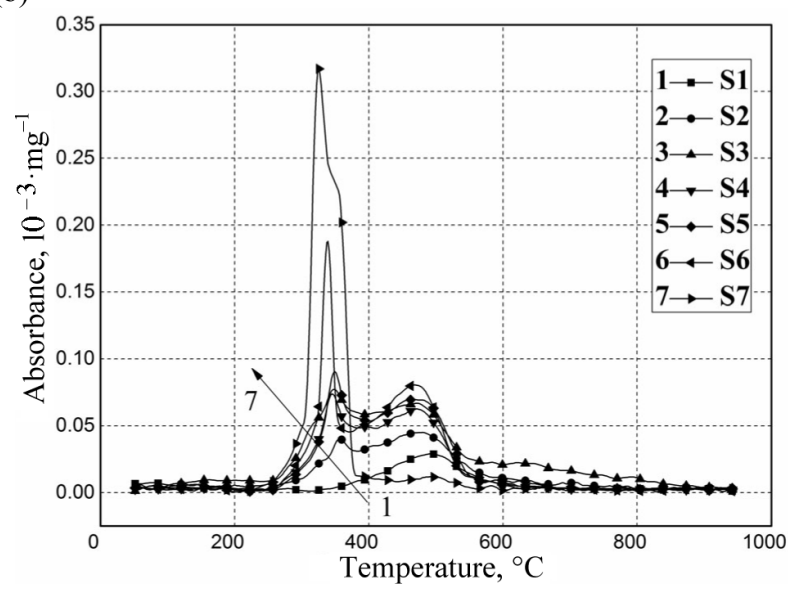

(c)

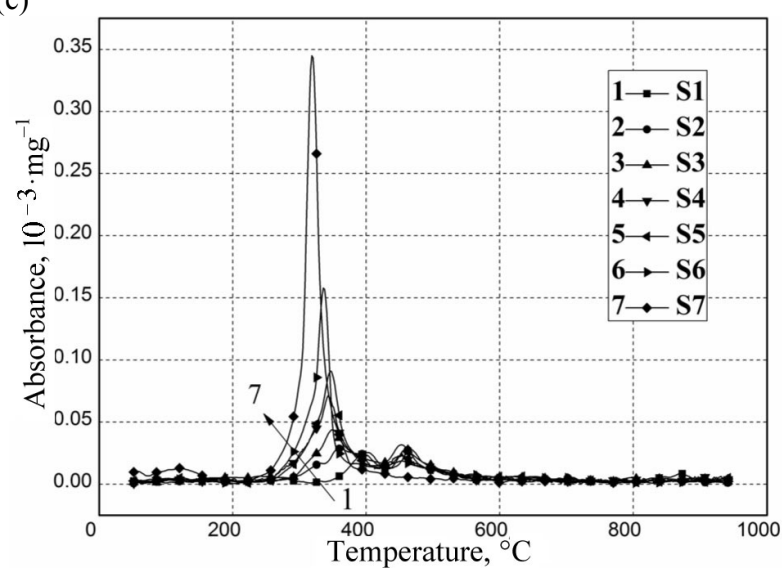

(d)

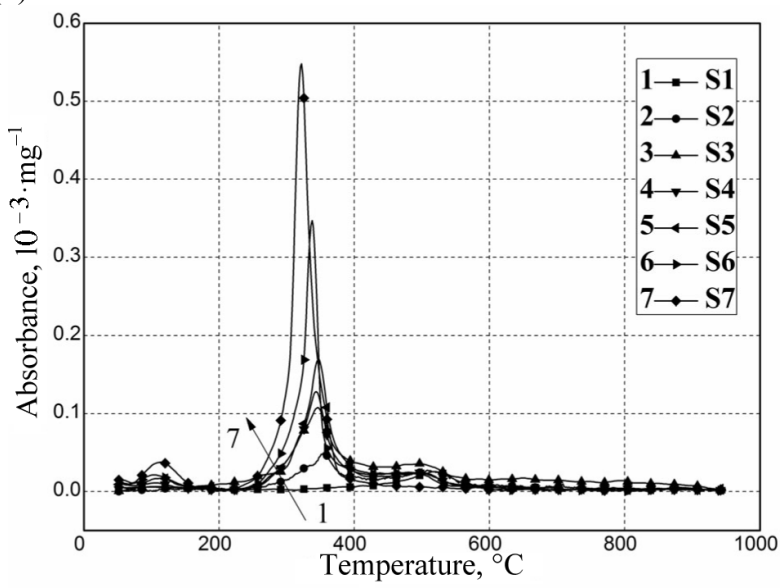

Fig. 8. FTIR absorbance curves for some specific gaseous products during the combustion of samples S1 to S7: (a) $\mathrm{CO}_{2}\left(2306 \mathrm{~cm}^{-1}\right)$; (b) $\mathrm{CO}\left(2182 \mathrm{~cm}^{-1}\right)$; (c) $\mathrm{SO}_{2}$ $\left(1374 \mathrm{~cm}^{-1}\right)$; (d) $\mathrm{NO}_{2}\left(1510 \mathrm{~cm}^{-1}\right)$. 


\section{Conclusions}

1. The co-combustion of oil shale semi-coke and sawdust undergoes four stages. Parameters, such as ignition temperature, burning temperature, maximum/average burning rate and combustion performance index, can be used to evaluate the combustion performance of samples. The samples performance is found to improve gradually with increasing sawdust proportion in the blend.

2. The activation energy, $E$, is determined using the Miura integral method based on the distributed activation energy model (DAEM). The value of $E$ decreases with the proportion of sawdust mixed. At a residue/sawdust ratio of 8:2, the value of $E$ remains low and varies only slightly, which favours combustion.

3. The Gram-Schmidt curves are in agreement with the DTG curves, but the high heating rate negatively affets the gas release. The gaseous emissions in the low-temperature stage are derived by the pyrolysis and combustion of organic volatiles. The gaseous emissions in the mediumtemperature stage are mainly produced by the pyrolysis and combustion of inorganic compounds.

4. $\mathrm{CO}_{2}$ is the main product derived from cellulose combustion, lignin pyrolysis, and fixed carbon or chars combustion. $\mathrm{SO}_{2}$ is derived from the sulfur-containing heterocyclic organic compounds and the residual thiophene material. $\mathrm{NO}_{\mathrm{x}}$ is mainly composed of $\mathrm{NO}_{2}$, which is produced by the decomposition of nitrogen-containing heterocyclic aromatic hydrocarbons, nitrate and cyanide.

\section{Acknowledgments}

This work was supported by the Program for Changjiang Scholars and Innovative Research Team in University (IRT13052), and the National Natural Science Foundation of China (51276034).

\section{REFERENCES}

1. Li, S. Y., He, J. L., Hou, J. L., Wang, W., Qian, J. L. Current Status of the World's Exploration and Utilization of Oil Shale - A Review of Two Oil Shale International Symposiums held in 2014 Global Oil Shale Exploration. SinoGlobal Energy, 2015, 20(1), 25-32 (in Chinese).

2. Trikkel, A., Kuusik, R., Martins, A., Pihu, T., Stencel, J. M. Utilization of Estonian oil shale semicoke. Fuel Process. Technol., 2008, 89(8), 756-763.

3. Raukas, A., Punning, J.-M. Environmental problems in the Estonian oil shale industry. Energy Environ. Sci., 2009, 2(7), 723-728. 
4. Han, X. X., Kulaots, I., Jiang, X. X., Suuberg, E. M. Review of oil shale semicoke and its combustion utilization. Fuel, 2014, 126(15), 143-161.

5. Kuusik, R., Martins, A., Pihu, T., Pesur, A., Kaljuvee, T., Prikk, A., Trikkel, A., Arro, H. Fluidized-bed combustion of oil shale retorting solid waste. Oil Shale, 2004, 21(3), 237-248.

6. Kaljuvee, T., Kuusik, R., Trikkel, A., Maljukova, N. Behavior of sulphur compounds at combustion of oil shale semicoke. Oil Shale, 2003, 20(2), 113-125.

7. Wang, Q., Zhao, W. Z., Liu, H. P., Jia, C. X., Li, S. H. Interactions and kinetic analysis of oil shale semi-coke with cornstalk during co-combustion. Appl. Energ., 2011, 88(6), 2080-2087.

8. Wang, Q., Wang, X. D., Liu, H. P., Jia, C. X. Study of the combustion mechanism of oil shale semi-coke with rice straw based on Gaussian multi-peak fitting and peak-to-peak methods. Oil Shale, 2013, 30(2), 157-172.

9. Sun, B.-Z., Wang, Q., Shen, P.-Y., Qin, H., Li, S.-H. Kinetic analysis of cocombustion of oil shale semi-coke with bituminous coal. Oil Shale, 2012, 29(1), 63-75.

10. He, H. R., Weng, Q. Ownership, autonomy, incentives and efficiency: Evidence from the forest product processing industry in China. J. Forest Econ., 2012, 18(3), 177-193.

11. Auxenfans, T., Buchoux, S., Larcher, D., Husson, G., Husson, E., Sarazin, C. Enzymatic saccharification and structural properties of industrial wood sawdust: Recycled ionic liquids pretreatments. Energ. Convers. Manage., 2014, 88, 1094-1103.

12. Wang, Q., Wang, X. D., Jia, C. X., Liu, H. P. Study on reaction mechanism of co-combustion of oil shale semi-coke and corn stalks by the absolute reaction rate theory. Proceedings of the CSEE, 2013, 33(5), 28-34 (in Chinese).

13. Varol, M., Atimtay, A. T., Bay, B., Olgun, H. Investigation of co-combustion characteristics of low quality lignite coals and biomass with thermogravimetric analysis. Thermochim. Acta, 2010, 510(1-2), 195-201.

14. Özgür, E., Miller, S. F., Miller, B. G., Kök, M. V. Thermal analysis of co-firing of oil shale and biomass fuels. Oil Shale, 2012, 29(2), 190-201.

15. Qian, W., Xie, Q., Huang, Y. Y., Dang, J. T., Sun, K. D., Yang, Q., Wang, J. C. Combustion characteristics of semicokes derived from pyrolysis of low rank bituminous coal. Int. J. Mining Sci. Technol., 2012. 22(5), 645-650.

16. Wang, Q., Wang, H. G., Sun, B. Z., Bai, J. R., Guan, X. H. Interactions between oil shale and its semi-coke during co-combustion. Fuel, 2009, 88(8), 15201529.

17. Shen, D. K., Gu, S., Jin, B. S., Fang, M. X. Thermal degradation mechanisms of wood under inert and oxidative environments using DAEM methods. Bioresource Technol., 2011, 102(2), 2047-2052.

18. Miura, $K$. A new and simple method to estimate $f(E)$ and $\mathrm{k}_{0}(E)$ in the distributed activation energy model from three sets of experimental data. Energ. Fuel., 1995, 9(2), 302-307.

19. Gao, N. B., Li, A. M., Quan, C., Du, L., Duan, Y. TG-FTIR and Py-GC/MS analysis on pyrolysis and combustion of pine sawdust. J. Anal. Appl. Pyrol., 2013, 100, 26-32.

20. Yan, J. W., Jiang, X. M., Han, X. X., Liu, J. G. A TG-FTIR investigation to the catalytic effect of mineral matrix in oil shale on the pyrolysis and combustion of kerogen. Fuel, 2013, 104, 307-317. 
21. Peralta, M. A., Milt, V. G., Cornaglia, L. M., Querini, C. A. Stability of Ba, $\mathrm{K} / \mathrm{CeO}_{2}$ catalyst during diesel soot combustion: Effect of temperature, water, and sulfur dioxide. J. Catal., 2006, 242(1), 118-130.

22. Sun, B. Z., Wang, Q., Li, S. H., Wu, X. H., Sun, J., Sun, B. M. Experiment Study on Combustion Performance of Oil Shale and Semi-coke Blends. Proceedings of the CSEE, 2006, 26(20), 108-112 (in Chinese).

23. Lu, L., Jin, Y. Q., Liu, H. M, Ma, X. J., Yoshikawa, K. Nitrogen evolution during the co-combustion of hydrothermally treated municipal solid waste and coal in a bubbling fluidized bed. Waste Manage., 2014, 34(1), 79-85.

24. Yagi, S., Kunii, D. Fluidized-solids reactors with continuous solids feed-I: Residence time of particles in fluidized beds. Chem. Eng. Sci., 1961, 16(3-4). 364-371.

Presented by S. Li and A. Paist

Received November 12, 2014 